\title{
Numerical Research on the Vortex Center on the Forward-Swept 3-D Wind Turbine Blades at Low Rotational Speed
}

\author{
Sutrisno ${ }^{1}$, Setyawan Bekti Wibowo ${ }^{1,2} \&$ Sigit Iswahyudi1 ${ }^{1,3}$ \\ ${ }^{1}$ Department of Mechanical and Industrial Engineering, Faculty of Engineering, Universitas Gadjah Mada, \\ Yogyakarta 55281, Indonesia \\ ${ }^{2}$ Department of Mechanical, Vocational College, Universitas Gadjah Mada, Yogyakarta 55281, Indonesia \\ ${ }^{3}$ Department of Mechanical Engineering, Universitas Tidar, Magelang 56116, Indonesia \\ Correspondence: Sutrisno, Department of Mechanical and Industrial Engineering, Faculty of Engineering, \\ Universitas Gadjah Mada, Yogyakarta 55281, Indonesia. Tel: 62-896-2266-9341. E-mail: sutrisno@ugm.ac.id
}
Received: October 10, 2018
Accepted: Nov. 1, 2018
Online Published: November 16, 2018
doi:10.5539/mas.v12n12p80
URL: https://doi.org/10.5539/mas.v12n12p80

The research is financed by Department of Mechanical \& Industrial Engineering, Universitas Gadjah Mada, Indonesia.

\begin{abstract}
This paper studies the CFD simulation of forward three-dimensional (3-D) horizontal axis wind turbine (HAWT) blades. Using logarithmic grid and Q-criterion to learn the vortex dynamics around the blades at low rotational speed. The computational fluid dynamics (CFD) simulation uses Q-criterion to probe vortices and logarithmic grid to emphasize the micro-gridding effect of the turbulent boundary layer. The visualization \& measurement of the simulation results give the coefficient of pressure (Cp). For forward 3-D wind turbine blade, at low rotational speed, the strongly accelerated laminar region surrounds the lower blade, and the decelerated tip blade region coalesce each other give rise to a reverse limiting streamline, eroding the laminar region further until a little is left on the tip of the blade. The "reverse limiting streamline" grows inward radially, the area is narrowing closing to the leading edge of the blade tip. The second side of the rolled-up vortex appears the velocity ratio (Uc/Ulocal) of the second vortices are higher than the main vortex cores. For radius $R=1.547 \mathrm{~m}, \mathrm{U}=12 \mathrm{~m} / \mathrm{s}$, at $210 \mathrm{RPM}, \mathrm{C}_{\mathrm{L}}$ and $C_{D}$ values reach a maximum with fully laminar tip conditions. While at $120 \mathrm{RPM}$, the $\mathrm{C}_{\mathrm{L}}$ and $\mathrm{C}_{\mathrm{D}}$ values reach a minimum in the absence of laminar tips. The results show the detailed vortex dynamic pattern surround the blades, give more understanding to design laminar 3-D blade toward a noiseless wind turbine system.
\end{abstract}

Keywords: CFD model, Q-criterion, forward, 3-D wind turbine blades, structured grid, rolled-up vortex, vortex center

\section{Introduction}

The power of 3-D HAWT blade models with backward-swept has been investigated, and the stream designs have been verified using visualization of the stream. The blade structures are designed employing the distributions of chord and twist following the formula of Schmitz. Formerly the sliced of HAWT blades were uniform as divided independently as there was not any exchange of momentum span wisely. Testing of performance and design of the blade were performed (Bai, Hsiao, Li, Huang, \& Chen, 2013; Plaza, Bardera, \& Visiedo, 2015; Singh \& Ra, 2013; Velázquez et al., 2014). Substantial involvement of German and Russian experts Joukowsky, Glauert had to be also documented (Okulov, Sørensen, \& Wood, 2014). Pumping effects and Coriolis force took part importance roles (Hu, Hua, \& Du, 2006).

The 3-D HAWT blade model performance has been investigated stresses on the phenomenon of stall delay in combination with back-swept of the HAWT blade models. The stall delays have been recognized in 3-D HAWT blade models. It was caused by the rolled-up vortex effects caused by triangular-hubs, as front-edge vortices caused essential roles (Gursul, Wang, \& Vardaki, 2007; Han \& Kinnas, 2013; Nelson \& Pelletier, 2003).

CFD simulation applying turbulence models was performed, in order to explore the stream mechanism around the HAWT blades, many turbulence forms were employed, including "Detached eddy simulation" (DES) model. Close 
to the boundary, DES needs very small gridding in the boundary, therefore logarithmic-meshes, and structured gridding was needed. Chengdu has been investigated to measure the fuselage effects, implementing Q-criterion, to model fighter aircraft. It is found that using Q-criterion, one can justify the accuracy of the simulation results to optimize the $\mathrm{y}+$ size.

Detached eddy simulation has solved several problems extensively. The delayed DES of a stalled flow over NACA0012 airfoil using high order schemes has been studied (Im \& Zha, 2011). Flow behind an isolated propeller has been simulated(Muscari, Di Mascio, \& Verzicco, 2013). A DES has been performed based on the v2-f model (Jee \& Shariff, 2014). A comprehensive study of DES has been done (Mockett, 2008; Morton et al., 2004; Travin, Shur, Strelets, \& Spalart, 1999). DES of the flow, behind the propeller, has been investigated (Muscari \& Mascio, 2013). Squires (Morton et al., 2004) has demonstrated the perspectives of DES. A qualified study of RANS DES and LES of internal torque converters flows has been done (Liu, Liu, \& Ma, 2015). Larson has shown the prospect of using DES and LES in engineering and the research (Larsson \& Wang, 2014).

Zhang et al. have learned the characteristics of HAWT blades with a sinusoidal front- edge (Zhang \& Wu, 2012). Dong et al. have conducted DNS study on identification methods of three vortex (Dong, Yang, \& Liu, 2017). Dobrev and B. Maalouf, has investigated the wind turbine vortex structure (Dobrev \& Maalouf, 2008). Model et al. has performed a CFD simulation of a floating offshore wind turbine system(Model et al., 2012).

This paper demonstrated the CFD simulation results using DES to forward 3-D HAWT blade model. The highly accurate scheme was employed in this research, using structured CFD scheme. The paper would explain the stream mechanism where the stall develops, and it propagates. This paper would elucidate the mechanism why the blade edge of the lowermost section is distressed from strongly decelerated distress, and the blade lip of the uppermost section is suffered from strongly accelerated distress as exposed by Sutrisno et al. (2016).

\section{Numerical Method}

\subsection{Wind Turbine Design}

In this simulation research, the procedure of boundary element method has been applied to design the configuration of the HAWT blades. The system had 3 blades and used airfoil NACA 4412 throughout the length of their spans. The distributions of the pitch angles and the spanwise of the chord lengths were approximated using the BEM optimum spreading (Equations (1) and (2)), as presented in Figure 1. The experiment uses a HAWT blade of R = $1.549 \mathrm{~m}$, where the 3-D model is shown in Figure 2.

$$
\beta_{r}=\frac{2}{3} a \tan \left[\frac{1}{\lambda_{D}\left(\frac{r}{R}\right)}\right]-\alpha_{D}, \text { and }\left(\frac{c}{R}\right)_{r}=\frac{16 \pi\left(\frac{r}{R}\right)_{r}}{C_{L, D}}\left\{\sin \left\{\frac{1}{3} a \tan \left[\frac{1}{\lambda_{D}\left(\frac{r}{R}\right)_{r}}\right]\right\}\right\}^{2}
$$

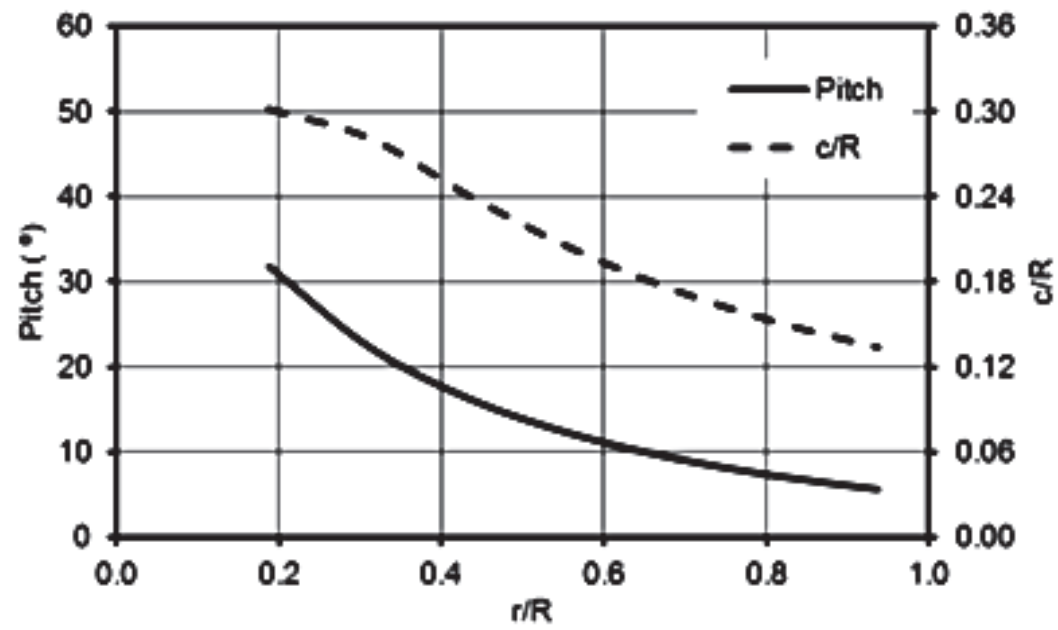

Figure 1. Designed pitch and normalized chord lengths spanwise (Sutrisno, Iswahyudi, \& Wibowo, 2018). 


\subsection{Simulation Methods}

The computational domain construction started with the formation of a HAWT blade CAD model and divided the area into blocks. The block section was then sliced to become net as exposed in Figure 2. The net structure applied was a hexahedral arranged net with H-shaped type on the exterior of the HAWT blade with the wall function principle of $\mathrm{y}^{+}=4$. It meant that the first net depth on the partition was $0.0002 \mathrm{~m}$. Computational area formation used periodic $120^{\circ}$ boundary conditions. The quantity of cells in the computational filed of the blades was around $1,200,000$ cells after a series of net independence tests.

In this investigation, the gas was presumed to be steady state, incompressible. The mass conservation equation and the momentum equation were employed with "Moving Reference Frame" mode. The fluid was with $1,225 \mathrm{~kg} / \mathrm{m} 3$ density and $0,000017894 \mathrm{~kg} / \mathrm{ms}$ viscosity. The discrete algebraic equations solving method was Semi ImplicitMethod for Pressure Linked Equation method using the SST equation turbulence model.

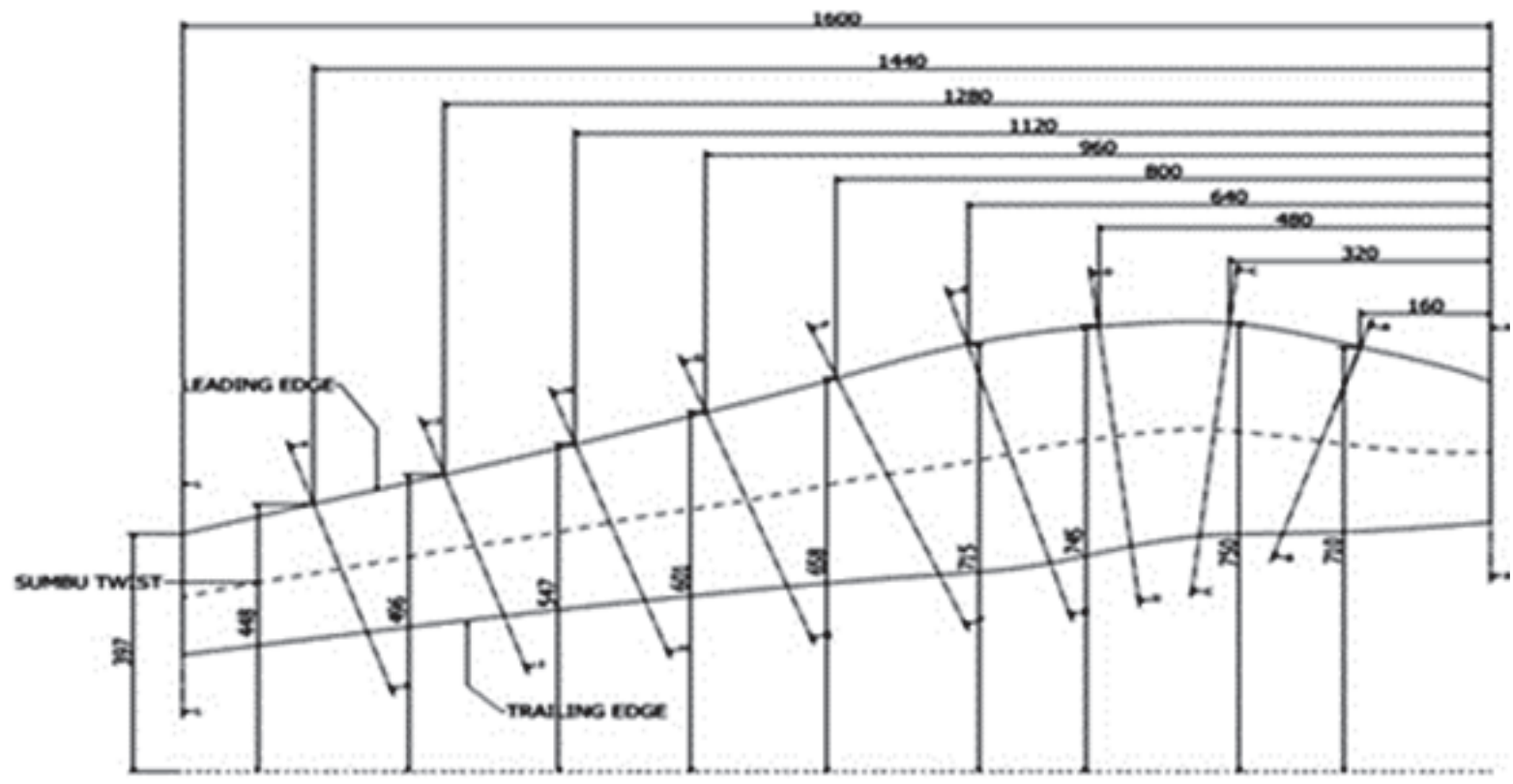

Figure 2. The model used in this study is a 3-D wind turbine blade with $1.549 \mathrm{~m}$ dimensions refer to the actual size

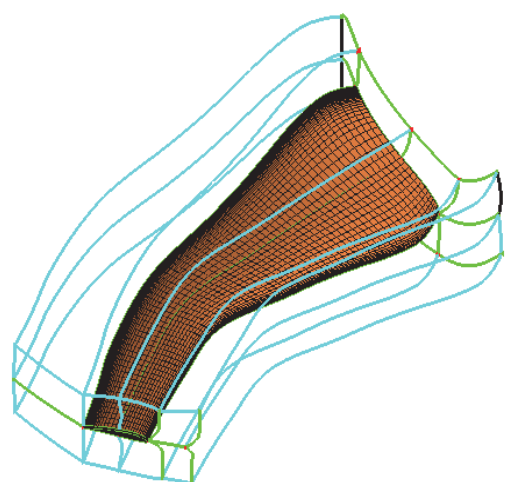

(a)

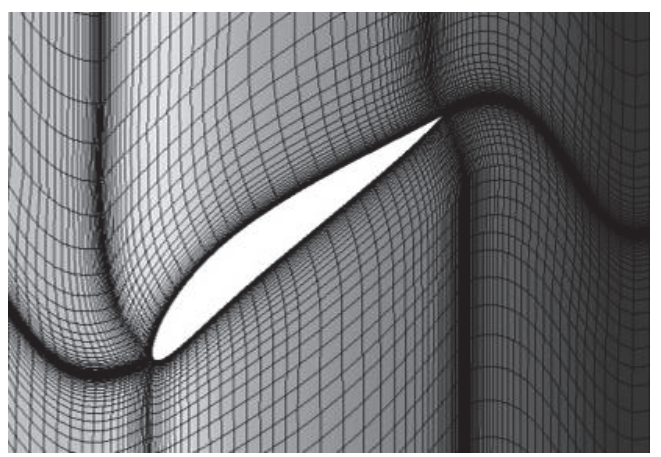

(b) 


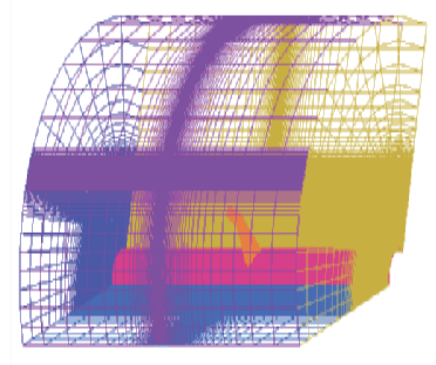

(c)

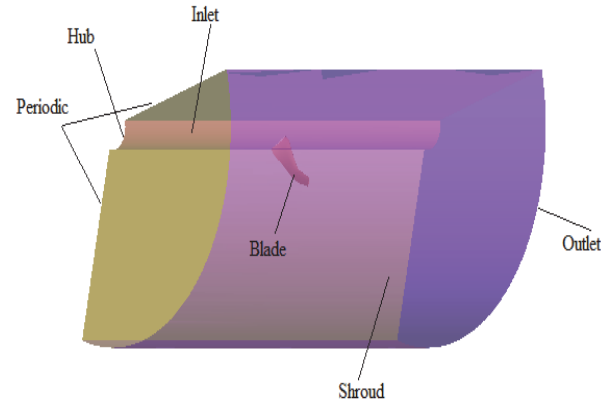

(d)

Figure 3. Computational mesh design (Sutrisno, Deendarlianto, et al., 2018). a) The blade, b) blocking strategy and c) H-shape mesh at blade surface, and d) computational domain with $120^{\circ}$ periodic boundary conditions

\subsection{Result Interpretation Procedure}

The 3-D wind turbine blade results analyze consisted of a) flow visualization step, namely plotting the limiting streamline, and vortex center flow visualization and b) measure the results along the blade, namely i) the vortex center strength, ii) the trajectory of the vortex core, iii) distribution of surface pressure, and $C_{L}$ and $C_{D}$ of the blade. Flow visualization includes plotting the limiting streamline, footprint drawing. Here, it will also be described the changes in the turbulent zone, laminar zone, acceleration or deceleration zone, and the rolled-up vortex existence. Next will also be shown the stream visualization plot of the main vortex core.

The measurement result consists of the strength measurement of the vortex center is the velocity of the axial vortex center $\mathrm{U}_{\mathrm{o}} / \mathrm{U}_{\text {local }}(\mathrm{z})$ and the pressure coefficient, $\mathrm{C}_{\mathrm{p}}$ of the vortex core, or measures the pressure coefficient of the center of the total pressure loss over the area in consideration. Spanwise and trajectory location measurement of the vortex core or the center of the total pressure loss. Surface pressure distribution at $30 \%$ and $60 \%$ of the area under review. The measurable result is intended to provide quantitative quantities of whether the vortex center is called a vortex core if $\mathrm{U}_{\mathrm{c}} / \mathrm{U}_{\text {local }}(\mathrm{z})$ is greater than or equal to 1 , meaning that the vortex tip or rolled-up vortex is sharp enough to impact laminarization or stall delay on the turbulent area it hears.

Trajectory vortex is quite close to the surface, so it has induced negative pressure and strong induction lifts, this can be seen in $C_{L}$ and $C_{D}$ distributions along the area under review. The results of the measurable result-based analysis can be remixed with the visualization results. By considering the results of the limiting streamline or footprint, and the results of vortex center visualization one can observe the vortex tip, rolled-up vortex, whether rolled-up vortex or not, whether the rolled is weak or strong to produce laminarization or stall delay for the area passed.

\section{Results and Discussion}

\subsection{Numerical Validation}

Independent test for the forward HAWT blade was conducted, we measured the torque of the HAWT blade for a different number of the cell from 650,000 to 1,350,000, and it gives stable values, as shown in Fig. 4.

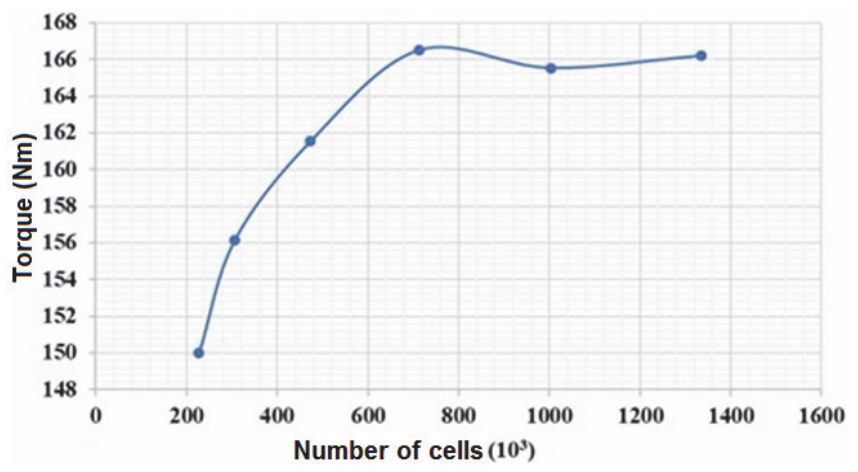

Figure 4. Independent test for forward HAWT blade measured the torque for a different number of the cell from 650,000 to $1,350,000$. 


\subsection{Results of Numerical Simulation}

\subsubsection{Limiting Streamline Flow Visualization}

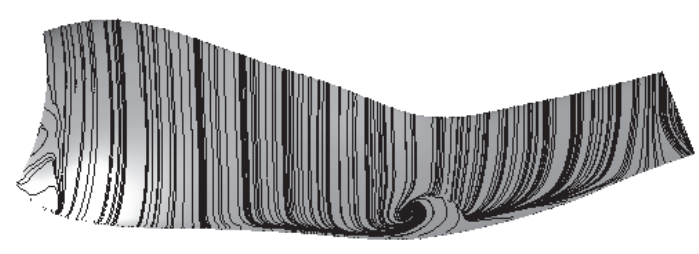

a) $210 \mathrm{RPM}, \mathrm{TSR}=2.872$, Large laminar region

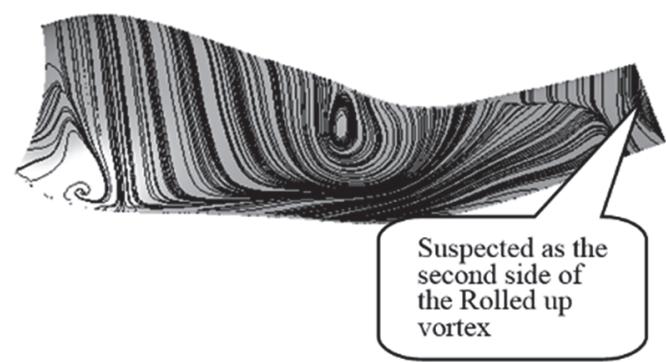

c) $160 \mathrm{RPM}, \mathrm{TSR}=2.161$ thin laminar region

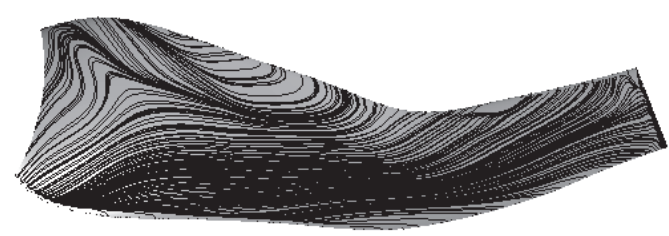

e) 90RPM, TSR $=1.215$, no laminar region

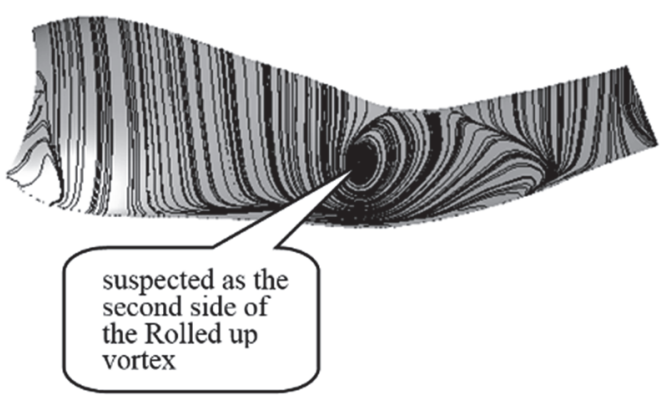

b)180RPM, TSR $=2.431$, Large laminar region

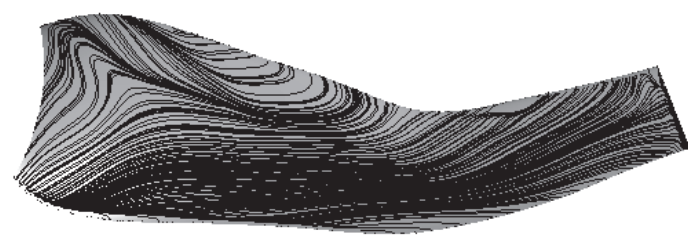

d)120 RPM, TSR $=1.621$, no laminar region

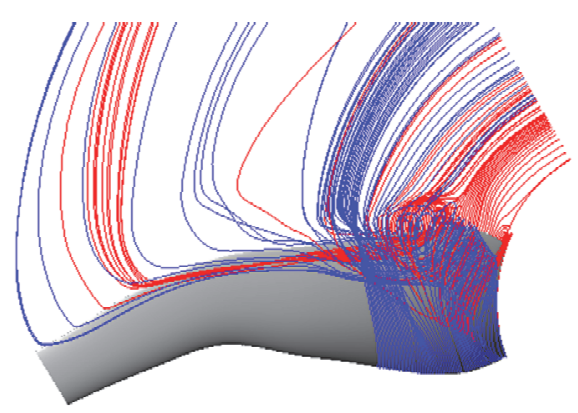

f) Pathline at $12 \mathrm{~m} / \mathrm{s}$ and 120 RPM

Figure 5. Limiting streamlines at the surface of the blade. The sample data was taken at a speed of $12 \mathrm{~m} / \mathrm{s}$ on the transition area with variation $210,180,160,120$, and 90 RPM. Toward lower pictures, TSR reduced, the

blade rotation was going slower as the load grew heavier than before and the laminar region gradually disappeared 


\subsubsection{Vortex Core Flow Visualization}

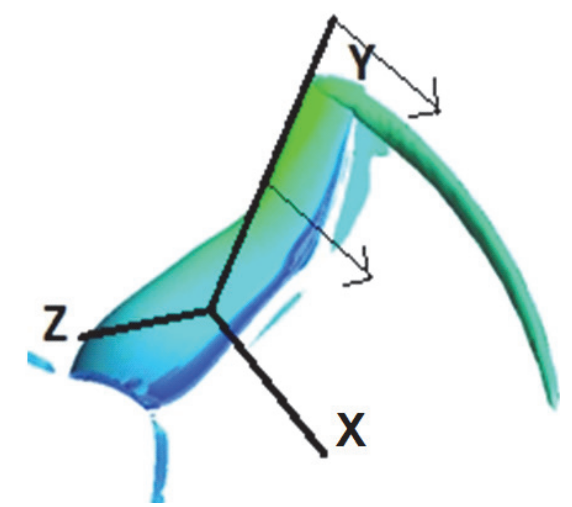

a) $240 \mathrm{RPM}, \mathrm{TSR}=3.242$, Large laminar region

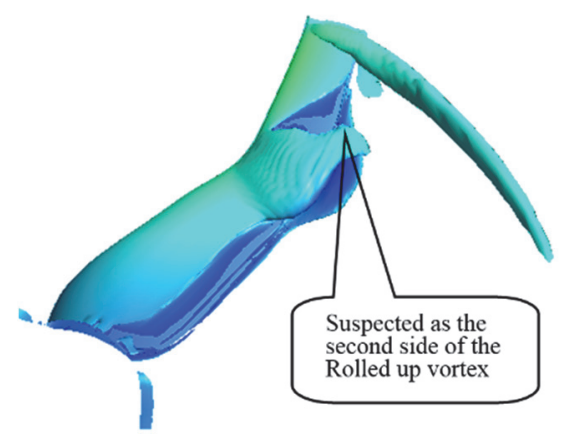

c) $180 \mathrm{RPM}, \mathrm{TSR}=2.431$, Large laminar region

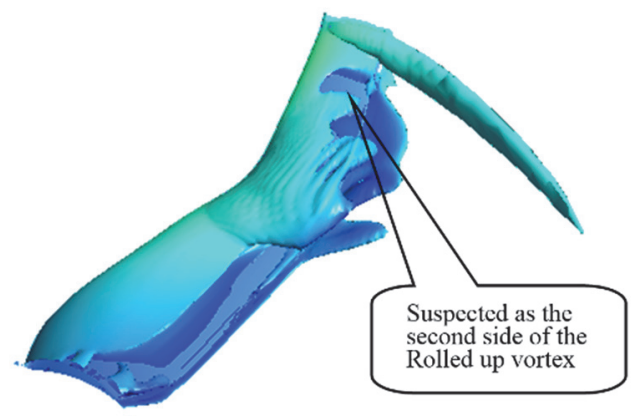

e) $160 \mathrm{RPM}, \mathrm{TSR}=2.161$, thin laminar region

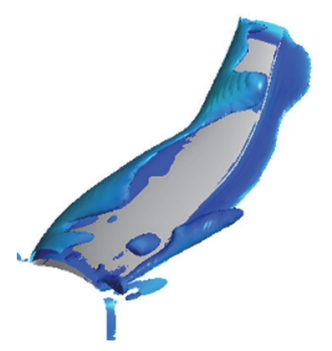

g) $90 \mathrm{RPM}, \mathrm{TSR}=1.215$, no laminar region

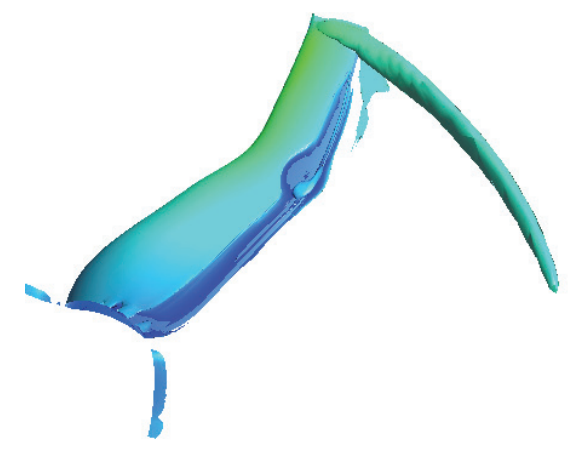

b) $210 \mathrm{RPM}, \mathrm{TSR}=2.837$, Large laminar region

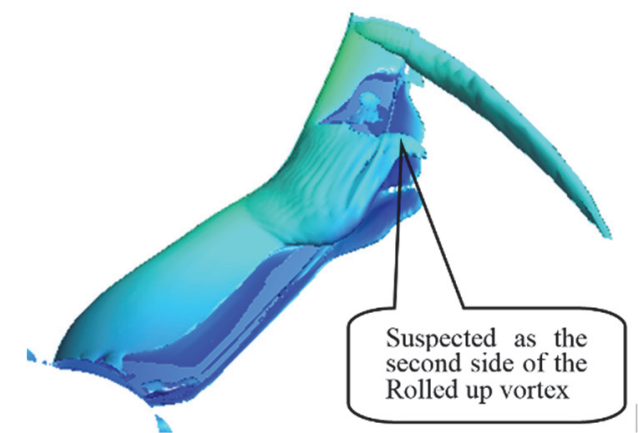

d) $165 \mathrm{RPM}, \mathrm{TSR}=2.512$, thin laminar region

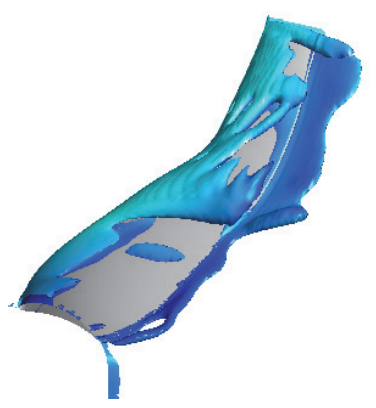

f) 120 RPM TSR=1.621, no laminar region

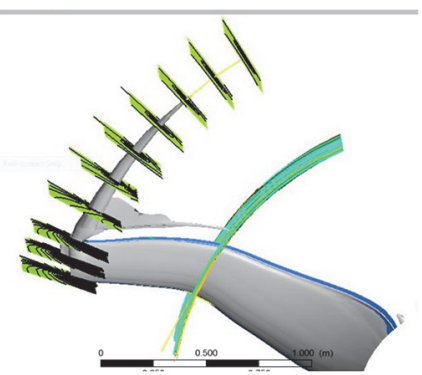

h) how to measure the vortex core due to a vortex tip at the end of the forward wind turbine blade

Figure 6. Vortex-core visualization samples were taken at speeds of $12 \mathrm{~m} / \mathrm{s}$ in the transition area variation of 240 , $210,180,165,160,120$ and 90 RPM. Toward lower pictures, TSR reduced, the blade rotation was going slower as the load grew heavier than before and the laminar region gradually disappeared. 


\subsubsection{Limiting Streamline and Vortex Core Flow Visualizations}

Fig. 6a-6g visualizes vortex cores ranging from $240-90 \mathrm{RPM}$ at $\mathrm{U}=12 \mathrm{~m} / \mathrm{s}$. The figure shows the correlation between transitions 180, 160, 120 and 90 RPM, Fig. 5b-5d, where the laminar area on the tip is still broad, shrinking, narrowing, and finally lost. It is also related to the existence of vortex cores, Fig. $6 \mathrm{c}-6 \mathrm{~g}$, where the vortex core is getting smaller and eventually disappeared. The flow mechanism around the forward wind turbine blade in Fig. 5 shows that the vortex tip of the blade acts as if it resembles a rolled-up vortex of a delta triangle. This is obtained by interpreting the footprint of the limiting streamline, in Fig. 5, for $U=12 \mathrm{~m} / \mathrm{s}$ and rotation of 210, 180, 160, 120 RPM.

In the field surround a 3-D forward HAWT blade, Fig. 5a, there is a strongly accelerated laminar region in the base of the blade and a strongly decelerated laminar region at the middle region of the blade. As the blade rotation drags slower to moderate speeds, a "reversed limiting stream," an eroding stall area, grows at the blade elbow area, where the two zones meet, as shown in Fig. 5b-5c. As the top zone which encroached by the reversed stall area, the remaining laminar region is the leading-edge area towards the blade tip. It is a decelerated laminar region. At last, the laminar area in the leading-edge region of the blade tip becomes the connecting channel toward the blade-tip outward vortex-center. At the other end, the laminar area in the leading-edge region is directly adjacent to the "reversed limiting streamline."

At higher rotation around 165 and 160 RPM, as shown in Fig. 6, the reversed vortex starts to be suspected as the second side of the rolled-up vortex, the second vortex center. Its axial vortex center speed is higher than the main axial vortex center, as shown by the picture of "limiting-streamline" Fig. 5 and vortex center Fig. 6 . When compared with the backward HAWI blade, (Sutrisno, Deendarlianto, et al., 2018), the "limiting streamlined" path of backward HAWI blade grows towards the tip radially, while on the forward HAWI blade the limiting streamline flows flips, spreads forward, from tip to the hub. By knowing the characteristics of limiting streamline disasters, it is easy to understand how to reduce energy wasted with vortex tips.

\subsubsection{Vortex Core, Coefficient of Pressure (Cp), Radial Distribution of $C_{L}$ and $C_{D}$}

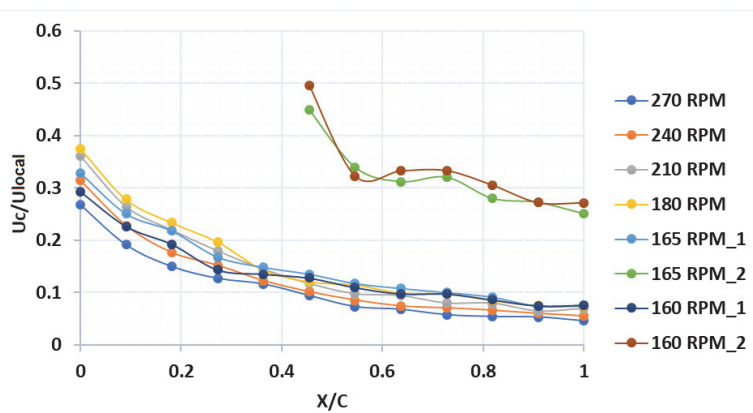

(a)

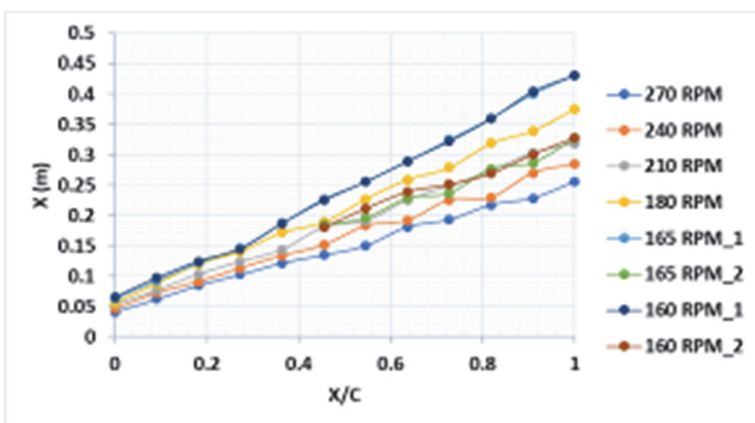

(c)

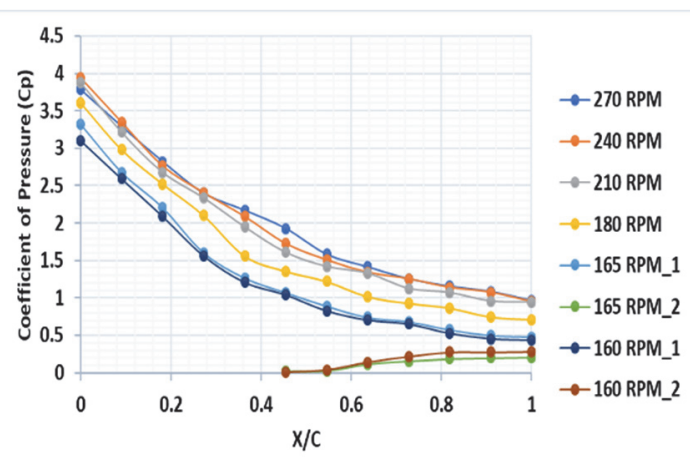

(b)

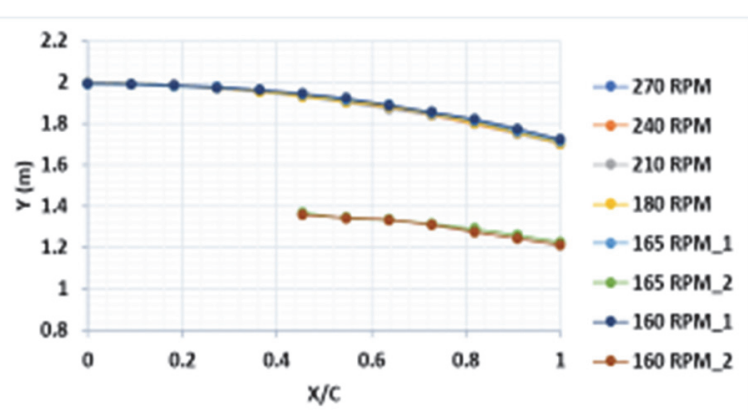

(d)

Figure 7. Graph of a) $C_{p}$ to $x / c$ for various RPMs at $12 \mathrm{~m} / \mathrm{s}$, b) velocity ratio variation of the axial vortex center velocity to the location reference speed Uc/Uloc, c) vortex center height, and d) spatial wise graph of the vortex center to $\mathrm{x} / \mathrm{c}$ for various RPMs at $12 \mathrm{~m} / \mathrm{s}$. 
Fig. 7a shows the velocity ratio variation of the axial vortex center velocity to the location reference speed $U_{\mathrm{c}} / \mathrm{U}_{\text {loc. }}$. Data samples were taken when the speed of $12 \mathrm{~m} / \mathrm{s}$ in the transition area with a variation of $210,180,160$, and 120 RPM. While Fig. $7 \mathrm{~b}$ shows the coefficient of pressure along the vortex center of the vortex tip at $U=12 \mathrm{~m} / \mathrm{s}$ for 270, 240, 210, 180, 165, and 160 RPM. Fig. 7c shows the vortex center height and Fig. 7d shows the spatial wise graph of the vortex center at various RPMs at $12 \mathrm{~m} / \mathrm{s}$. In Fig. 8 are shown the graph of a) the lift coefficient $\left(\mathrm{C}_{\mathrm{L}}\right)$, and b) the drag coefficient $\left(C_{D}\right)$ to the radial blade span at $12 \mathrm{~m} / \mathrm{s}$ at the transition-location of $210,180,160$, and 120 RPM.

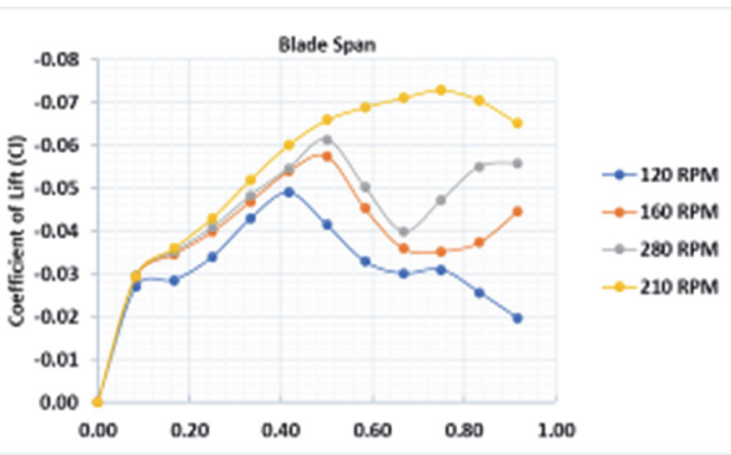

(a)

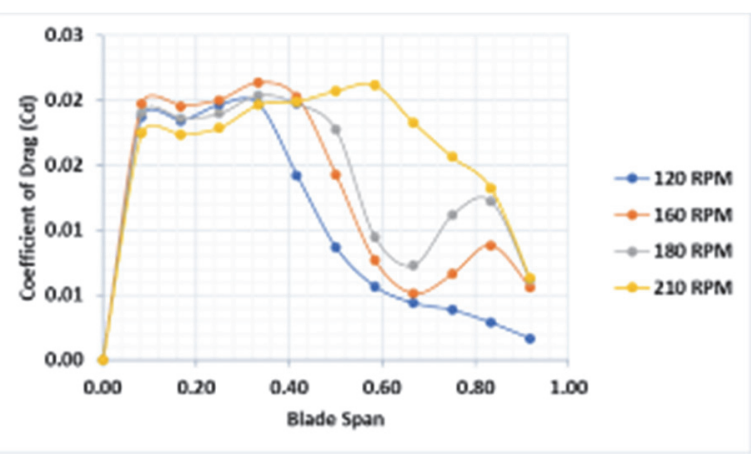

(b)

Figure 8. Graph of a) $\mathrm{C}_{\mathrm{p}}$ to $\mathrm{x} / \mathrm{c}$ for various RPMs at $12 \mathrm{~m} / \mathrm{s}$ at 210, 180, 160, and $120 \mathrm{RPM}, \mathrm{b}$ ) coefficient of lift with respect to $\%$ blade span at $12 \mathrm{~m} / \mathrm{s}$, and c) coefficient of drag with respect to $\%$ blade span at $12 \mathrm{~m} / \mathrm{s}$ on 210 , 180, 160, and 120 RPM.

At higher rounds around 165 and 160 RPM, as shown in Figure 8, starts to appear suspected as the second vortex center (starting with a lower RPM) with an axial vortex center speed higher than the main axial vortex center, as shown by the picture " limiting-streamline" Fig. 5 and vortex core Fig. 6. With an understanding of the characteristics of limiting streamline disasters, it is increasingly understood how to reduce energy wasted with vortex tips. From Fig. 8, it is understood that the decrease in RPM due to rising loads makes the $C_{L}$ and $C_{D}$ go down, and vice versa. When in Fig. 8 in combination with limiting streamline characters Fig. 7, it can be concluded that at low load, 210 RPM, the tip of the laminar blade is full, at the end it gives the highest $C_{L}$ and $C_{D}$. In contrast, at high loads, 120 RPM, the tip of the blade without the remaining laminar area, at the end gives the lowest $C_{L}$ and $\mathrm{C}_{\mathrm{D}}$.

Table 1. Characteristics comparison between 3-D forward wind turbine blade CFD model with $12 \mathrm{~m} / \mathrm{s}$. Lift coefficient $\mathrm{C}_{\mathrm{L}}$, derived from Fig. 4, the velocity ratio variation $\mathrm{Uc} / \mathrm{U}_{\text {local }}$ along the vortex core and pressure coefficient variation $\mathrm{Cp}$ along the vortex core at different blade rotation 270, 210, 180, 160, 1nd 120 RPM.

\begin{tabular}{ccccccc}
\hline & $\begin{array}{c}\text { Wind Turbine Blade } \\
(\mathrm{RPM})\end{array}$ & $270 \mathrm{RPM}$ & $210 \mathrm{RPM}$ & $180 \mathrm{RPM}$ & $160 \mathrm{RPM}$ & $120 \mathrm{RPM}$ \\
\hline & $\mathrm{Uc} / \mathrm{U}_{\text {local }} \max$ & 0.28 & 0.36 & 0.38 & 0.3 & - \\
& $-\mathrm{Cp} \max$ & 3.2 & 4.0 & 3.6 & 3.1 & 0.056 \\
\\
\hline
\end{tabular}

\section{Conclusion}

In this paper, a simulation of the forward 3-D HAWT blade is conducted to study the vortex dynamics characteristics of the flow surround turbine blades. The laminar region surrounds the lower blade is a strongly accelerated region, while the region surrounds the tip blade is strongly decelerated region. At high wind speeds, the more massive the load or, the slower the RPM, the area of the strongly accelerated region and strongly decelerated region coalesce together gives rise to a "reverse limiting streamline" phenomenon. This causes the laminar area to be further eroded so that only a little is left on the tip of the blade. The strongly decelerated laminar area is narrowing leads to the leading edge of the blade tip.

At the tip of the blade stays a vortex center, which is also a vortex tip. At the inner end of the laminar region, which 
borders on "reverse limiting streamline," appears the second side of the rolled-up vortex. The rolled-up vortex effect has an additional vortex center, which is detected starting from 180 RPM. The more massive the load, the slower the RPM, so the power increases. This can be seen at 160 and 165 RPM for $\mathrm{Uc} / \mathrm{U}_{\text {local }}$ from additional vortices which are higher than the main vortex centers.

When compared, the laminar area of the backward HAWT blade is crushed inward, especially on the blunt end blade. This caused the second additional vortex center, which was the result of the rolled-up vortex effect.

On the 3D forward HAWT blade, "reverse limiting streamline" grows inward radially. This event might cause a second core vortex, where $\mathrm{U}_{\mathrm{c}} / \mathrm{U}_{\text {local }}$ is larger than the main core vortex. However, this will be difficult to show and prove. When viewed from the $C_{L}$ and $C_{D}$ values, the value of both decreases when the RPM decreases. For a forward HAWT blade of radius, $1.547 \mathrm{~m}$ at $\mathrm{U}=12 \mathrm{~m} / \mathrm{s}, 210 \mathrm{RPM}, \mathrm{C}_{\mathrm{L}}$ and $\mathrm{C}_{\mathrm{D}}$ values reach a maximum with fully laminar tip conditions. While at 120 RPM, the $C_{L}$ and $C_{D}$ values reach a minimum in the absence of laminar tips.

\section{Nomenclature}

$\begin{array}{ll}\Omega & =\text { blade rotational speed }(\mathrm{RPM}) \\ \mathrm{U} & =\text { the air velocity }(\mathrm{m} / \mathrm{s}) \\ \mathrm{RPM} & =\text { the frequency of the rotor (rotation/minutes) } \\ \mathrm{TSR} & =\text { tip speed ratio } \\ \mathrm{R} & =\text { blade outer radius }(\mathrm{m}) \\ \mathrm{Cp} & =\text { coefficient of performance } \\ \rho & =\text { air density }(\mathrm{kg} / \mathrm{m} 3) \\ \mathrm{U}_{\infty} & =\text { free stream velocity }(\mathrm{m} / \mathrm{s}) \\ \mathrm{X} . \mathrm{y} & =\text { abscissa\& ordinate } \\ \Omega & =\text { constant angular velocity }(\mathrm{rad}) \\ \mathrm{C}_{\mathrm{D}} & =\text { drag coefficient } \\ \mathrm{C}_{L} & =\text { lift coefficient } \\ \mathrm{N} & =\text { blade number } \\ \beta & =\text { twist } \\ \alpha_{\mathrm{D}} & =\text { geometric angle of attack }(\mathrm{deg}) \\ \mathrm{Uc} / \mathrm{U}_{\text {local }}(\mathrm{z}) & =\text { velocity ratio } \\ \mathrm{c} & =\text { chord }\end{array}$

\section{Acknowledgement}

This research was funded by Department of Mechanical \& Industrial Engineering, Universitas Gadjah Mada, Indonesia, under the contract 1560/H1.17/TMI/LK/2016.

\section{References}

Bai, C. J., Hsiao, F. B., Li, M. H., Huang, G. Y., \& Chen, Y. J. (2013). Design of 10 kW Horizontal-Axis Wind Turbine (HAWT) Blade and Aerodynamic Investigation Using Numerical Simulation. Procedia Engineering, 67, 279-287. https://doi.org/10.1016/j.proeng.2013.12.027

Dobrev, I., \& Maalouf, B. (2008). Investigation of the wind turbine vortex structure. 14th Int Symp on Applications of Laser Techniques to Fluid Mechanics, (2003), 7-10.

Dong, Y., Yang, Y., \& Liu, C. (2017). DNS study on three vortex identification methods. AIAA SciTech Forum 55th AIAA Aerospace Sciences Meeting, (January). https://doi.org/10.2514/6.2017-0137

Gursul, I. Ã., Wang, Z., \& Vardaki, E. (2007). Review of flow control mechanisms of leading-edge vortices. Progress in Aerospace Sciences, 43, 246-270. https://doi.org/10.1016/j.paerosci.2007.08.001

Han, C., \& Kinnas, S. A. (2013). Study on the Wake Shape behind a Wing in Ground Effect Using an Unsteady Discrete Vortex Panel Method. Open Journal of Fluid Dynamics, 3(December), 261-265. https://doi.org/10.4236/ojfd.2013.34032

Hu, D., Hua, O., \& Du, Z. (2006). A study on stall-delay for horizontal axis wind turbine. Renewable Energy, 31(6), 821-836. https://doi.org/10.1016/j.renene.2005.05.002

Im, H.-S., \& Zha, G.-C. (2011). Delayed Detached Eddy Simulation of a Stall Flow Over NACA0012 Airfoil Using High Order Schemes. Proceedings of the 49th AIAA Aerospace Sciences Meeting Including the New Horizons Forum and Aerospace Exhibition, (January), 1-16.

Jee, S., \& Shariff, K. (2014). Detached-eddy simulation based on the v2-f model. In 7 Int Copnf ICCFD (Vol. 46, 
pp. 84-101). Hawai. https://doi.org/10.1016/j.ijheatfluidflow.2013.12.006

Larsson, J., \& Wang, Q. (2014). The prospect of using large eddy and detached eddy simulations in engineering design, and the research required to get there. Philosophical Transactions of the Royal Society A: Mathematical, Physical and Engineering Sciences, 372(2022), 1-15. https://doi.org/10.1098/rsta.2013.0329

Liu, C., Liu, C., \& Ma, W. (2015). Rans, detached Eddy simulation and large Eddy simulation of internal Torque converters flows: A comparative study. Engineering Applications of Computational Fluid Mechanics, 9(1), 114-125. https://doi.org/10.1080/19942060.2015.1004814

Mockett, C. (2008). A comprehensive study of detached-eddy simulation. PhD Thesis: TU Berlin.

Model, Q. C. M., Quallen, S., Xing, T., Carrica, P., Li, Y., \& Xu, J. (2012). CFD Simulation of a Floating Offshore Wind Turbine System Using, (August 2014), 1-8.

Morton, S. a, Kholodar, D., Billingsley, T., Forsythe, J. R., Wurtzler, K. E., Squires, K. D., ... Spalart, P. R. (2004). Multidisciplinary applications of detached-eddy simulation to separated flows at high Reynolds numbers. In Users Group Conference, 2004. Proceedings (pp. 103-111). https://doi.org/10.1109/DOD_UGC.2004.28

Muscari, R., Di Mascio, A., \& Verzicco, R. (2013). Modeling of vortex dynamics in the wake of a marine propeller. Computers and Fluids, 73, 65-79. https://doi.org/10.1016/j.compfluid.2012.12.003

Muscari, R., \& Mascio, A. Di. (2013). Detached Eddy Simulation of the flow behind an isolated propeller, (May), 218-226.

Nelson, R. C., \& Pelletier, A. (2003). The unsteady aerodynamics of slender wings and aircraft undergoing large amplitude maneuvers. Progress in Aerospace Sciences, 39(2-3), 185-248. https://doi.org/10.1016/S03760421(02)00088-X

Okulov, V. L., Sørensen, J. N., \& Wood, D. H. (2014). The rotor theories by Professor Joukowsky : Vortex theories. Progress in Aerospace Sciences, 1-28. https://doi.org/10.1016/j.paerosci.2014.10.002

Plaza, B., Bardera, R., \& Visiedo, S. (2015). Comparison of BEM and CFD Results for MEXICO Rotor Aerodynamics. Jnl. of Wind Engineering and Industrial Aerodynamics, 145, $115-122$. https://doi.org/10.1016/j.jweia.2015.05.005

Singh, R. K., \& Ra, M. (2013). Blade design and performance testing of a small wind turbine rotor for low wind speed applications, 50, 812-819. https://doi.org/10.1016/j.renene.2012.08.021

Sutrisno, Deendarlianto, Rohmat, T. A., Indarto, W., S. B., Iswahyudi, S., ... Djatmiko. (2018). The Structured and Unstructured CFD Characteristic Studies of 3-D Backward Wind Turbine Blades. In AIP Conference Proceedings (Vol. 040003). https://doi.org/10.1063/1.5049986

Sutrisno, S., Iswahyudi, S., \& Wibowo, S. (2018). Dimensional Analysis in Power Prediction of a Real Scale Wind Turbine Based on Wind Tunnel Torque Measurement of Small Scaled Models. Energies, 11(9), 1-13. https://doi.org/10.3390/en11092374

Travin, A., Shur, M., Strelets, M., \& Spalart, P. (1999). Detached-Eddy Simulations Past a Circular Cylinder. Flow Turbulence and Combustion, 63, 293-313. https://doi.org/10.1023/A:1009901401183

Velázquez, M. T., Vega, M., Carmen, D., Francis, J. A., Pacheco, L. A. M., \& Eslava, G. T. (2014). Design and Experimentation of a $1 \mathrm{MW}$ Horizontal Axis Wind Turbine. Journal of Power and Energy Engineering, 2014(January), 9-16. https://doi.org/10.4236/jpee.2014.21002

Zhang, R.-K., \& Wu, V. D. J.-Z. (2012). Aerodynamic characteristics of wind turbine blades with a sinusoidal leading edge. Wind Energy, 15(3), 407-424. https://doi.org/10.1002/we.479

\section{Copyrights}

Copyright for this article is retained by the author(s), with first publication rights granted to the journal.

This is an open-access article distributed under the terms and conditions of the Creative Commons Attribution license (http://creativecommons.org/licenses/by/4.0/). 